Univerzitet u Beogradu

Filološki fakultet

kujaca.miljan@gmail.com

\title{
O SOCIJALNOJ ANGAŽOVANOSTI I JUGOSLOVENSTVU POVODOM IVANA CANKARA
}

Ovaj napis se bavi pitanjima socijalne angažovanosti sa kojom se značajan broj Cankarevih djela dovodi u čvrstu vezu. Razmatra se Cankarevo životno i političko ubjeđenje. U kontekstu ratnih dešavanja i klasnih previranja, dotaknuto je pitanje jugoslovenstva. Govori se o Cankarevoj budnoj svijesti o stanju u društvu, o čvrstom uvjerenju u zajedničku sudbinu južnoslovenskih naroda i jasnom shvatanju o nužnosti zajedničke borbe protiv stranog okupatora, ali i protiv domaćih kapitalističkih ugnjetača, kao i borbe za samoodređenje i konačno ujedinjenje.

Ključne riječi: Cankar, književnost, društvo, angažovanost, jugoslovenstvo, rat

Obilježeni jubilej nas je podsjetio da Cankara iznova čitamo, da razbijemo svaki pogrešan dojam i iluzije, ako ih imamo, i nanovo njegova sačinjenja doživimo prisnim, svojim, jer je to uistinu naša najvjernija i najdosljednija hronika.

O klasiku je svagda izazovno govoriti, ali nije naročito lako, makar se vodila riječ tek o jednom fragmentu njegova bogatog života $\mathrm{i}$ djelovanja. A blagu sentimentalnost ovom prilikom teško je suzbiti, jer sâm pomen Cankareva imena sjeća na davnašnje djetinje utiske stečene nad čitankama, i to uz njegove kratke forme - na koje se, dosta nepravedno, obično svode asocijacije na ovog književnika - poput ,Skodelice kave" i „Desetice”.

Je li ta osobita sklonost slovenačkih književnika kratkim literarnim formama, međurodovima - crtici, noveli - potreba i namjerno insistiranje talenta da se u što sažetijem vidu izrazi kakva poruka ili je pak riječ o kakvu mazohističkom istupu koji sili piščeva leđa da u radu izdiru, da se grče i napinju nad mučnim porođajem zvanim stvaranje, nad kratkom pričom - najzahtjevnijim žanrom u svekolikoj literaturi jer zahtijeva sažetost i razvijen osjećaj za suvišnu riječ - kakav, s jakom 
motivikom, može produbiti sadržinu i proširiti se do romanesknog opsega, u kakav je Cankar rado zalazio?

Ljudi kao Cankar, očigledno po prirodi nepojmljivosti i trajno talasavih sudbinskih previranja, žive kratko, tek toliko da prokrče trasu sljedbenicima i da tim pohodom nadahnu. U kratkom životu decenije i stoljeća prožive, prizivajući ih iz budućnosti, proričući nam ono daleko čemu je, u momentu predskazanja, još rano da nastupi, a što se bliži, napredno i neumitno. Je li razlog tomu nadljudska njihova snaga, preobraćena u stvaralačku eruptivnost, objavljenu i, kao sve nagle nepogode, brzo stišanu, što traje u svom kratkom bljesku poput zapristajućih odjeka pri grmljavini, ali i kao predosjećaj pomračenjâ XX vijeka? Je li to ekspresija koja je pred zahtjevnim bjelinama hartije i marginama manifestâ i studentskih cjeduljica - tim nevinim, ubrzo izrešetanim zidovima i kapijama velike stvarnosti - sve mijene proživjela i padove i trijumfe u viziji stasalog genija prozrela?

Osjetiv disanje naziruće bune, još pritajene, sluteći mrdavosti miliona što su, zvečeći preteškim lancima, kao talasi jedan drugog podstičući, polako prišli i slovenačkoj obezličenoj grudi, Cankar se zauzeo da posvjedoči kako u dugotrajnoj okupaciji nije upokojen slobodarski duh u narodu što odavno tuđoj kruni služi. Stoga je kreposti životnog poziva poistovijetio s bitkom za nezavisnost, za pravo na samoopredjeljenje, borbom jednakom naporima usiljenih marševa. Zato Ivana Cankara s pravom nazivamo apostolom socijalne angažovanosti ${ }^{\text {(Matvejević }}$ 1977: 30), jer ako umjetnost, ovdje - književnost, sadrži smisao - vodio se on - onda bi trebalo sva na usluzi da bude pregnućima i koristima čovjeka, neizuzetog iz zajednice, da doprinosi konstruisanju novih shvatanja podmlađenog čovjeka. Cankaru nije trebalo dugo to da shvati, jer ga se, svjesnog vremena i prostora u kom je živio i kom je odbijao da robuje, nisu ticale individualne boljke intimnog svijeta samodovoljnih, već isključivo pojedinac kao ljudsko, dakle i društveno biće, koje se u procesu društvene djelatnosti potvrđuje i kao stvaralačko biće, dio snage što pokreće masu s kojom je u komunikativnoj vezi. Njegovo angažovanje obračun je sa stvarnošću, skladno izvajana osveta u ime klase potčinjenih. Uz temu piščeve angažovanosti, nameće se pitanje pragmatizma, kao i larpurlara prema kom se Cankar nije blagonaklono odnosio. Kasnije će se, u međuratnom dobu, iz tog predratnog podozre- 
nja izroditi otvorena negacija književnosti nesvrhovitosti larpurlara kao reprezenta vještačkih moralisanja prezrene više klase, svjedočanstva o njenoj nazadnosti, nekorisnog luksuza buržoaskog društva.

Takozvani „belle epoque”, taj produžetak odveć dugog XIX vijeka, bio je elegantan koračaj iz nemirnog stoljeća u još nemirnije, načinjen stopalom obuvenim u prečistu visoku potpeticu, dok su, u ime industrijalizacije, produbljivane klasne razlike i proširivani slani tokovi znoja radničkih ruku sa kožom zadebljalom i mrkom. Ne štedeći bolesna pluća, Cankar grmi: „Ako je igdje radnik bio sužanj, u našim slovenačkim krajevima bio je dva puta sužanj. Ponegdje su mu izrabljivali ruke i glavu, kod nas su povrh tog uzeli i ponos, odrekli mu dušu i odrezali jezik" (Цанкар 1950: 36). Na sve to, na svakodnevicu samootuđenog čovjeka bez potpune slobode, dolazi radikalna hermetička uobličenost aktuelnog larpurlartiste, udaljenog od osnovnog ljudskog poziva - da služi socijalnom buđenju i napretku - zatvorenog u apstrakcije koje preziru čovjeka na zemlji, šapućući mu, blatnjavom, da zastane i da se gladan divi ozvjezdanom nebu.

Od svake Cankareve polemike, najžešća kritika društva svakako je nevelik dramski opus, a među njima, posigurno, drama „Hlapci”, srpski rečeno - „Sluge”. Ona, primjer usklađenosti forme i sadržine, nameće se kao ispunjenje svrhe dramske literature, koju je isticao Francuz Mari-Žozef Šenje: ,Ja ću uvijek biti ubijeđen da je cilj drame da zadobije ljubav za vrlinu, zakone i slobodu, i da omrzne fanatizam i tiraniju" (Скерлић 1972: 32). Pisana neposredno, kao u jednom dahu, direktno se zalijeće u opšti nazadluk prosječnih građana - malograđana - neosviješćenih slijepih podanika vlasti združene s klerom - falsifikatorom izvornog hrišćanstva - koji koristi svoje moći u svrhu, marsksistički rečeno - izrabljivanja vjere.

Nekad poslije pada Italije, 1943, u ljubljanskom zatvoru zatočenici su izvodili „Lepu Vidu” Cankarevu, a njemački okupatori su se čudili što slovenački narod uopšte ima pisce, pa još dramske. A tršćanski Italijani, okupani renesansom, Slovence Primorce, graničare slovenskog limesa na zapadu, zvali su doslovno - „skjâvi”, tj. roblje. Između osta$\log$, i iz tog razloga su se Primorci selili s ognjišta (Һилас 1947: 197), bježeći od kandži rastućeg imperijalizma, docnije preobučenog u nešto tamnije košulje, ustremljenog da demarkacionim linijama raščereči i logorizuje 
gore kranjske i štajerske. A ptica ljubimica starih Slovena - predanja i istorije kazuju - bio je gavran, i to „vrani” u narodnoj pjesmi. Valjda je ta stara zla slutnja pripalila iskru tuge i u Cankarevim slovenskim očima, koje nisu svici što se u suton užegnu, a zorom redom gase, već plamičci vječite sjete, bježuće naše radovanje.

Da se posvetio sačinjenjima notnih zapisa i bilježenju taktova namjesto refleksivnih crtica i lirske proze, uvjeren sam da bi komponovao kao jedan drugi, opet Sloven, Frederik Šopen (Krleža 1972: 158-162), ne zbog zajedničke im boljke, slovenske uporne pratilje, podstanarke grudobolje, već zbog obnovljene romantičarske melanholije isplivale za fen d' sjekla.

Melanholija je, svakako, kažu, u karakteru kraškog predjela, dinarskih uzvisina, izdignutih nad samom obalom, što svojim vijencem nerazdruživo povezuju zemlje i narode pravcem sjeverozapad-jugoistok, počev od slovenačkog primorja, pa naniže, sprudovima Jadrana, putem nekadašnje orogeneze. „Dio smo velike porodice”, besjedi Cankar, ,koja stanuje od Julijskih Alpa do Egejskog mora (Цанкар 1950: 25) [...] dio raskomadanog plemena koje u životu čovječanstva ne može izraziti svoju vrijednost dok se ne udruži u cjelinu" (Цанкар 1950: 29). To je bilo jedino izbavljenje iz dolina šentflorijanskih i mnogih biljških parohija, ,ne vruća želja, nego čvrsto ubjeđenje" (Цанкар 1950: 30).

„Po krvi smo braća, po jeziku barem bratanci.” (Цанкар 1950: 29), kaže Cankar za Jugoslovene. Ako kroz vrijeme ne dijelismo istu državu i jedan jezik, dijelili smo istu sudbinu okupiranih, a među tim našim sudbinama sluga Jernej jednak je stradalnik Kočićevu Davidu Štrpcu, kao i svim pobrojanim i nepobrojanim kmetovima - s obje strane Sutle i od sve tri Morave - bilo onima iz Gupčeve bilo onima iz Karađorđeve seljačke bune, dignute u ime jevanđeljske jednakosti.

Jugoslovenstvo je bilo ideja koja nije dovoljno duboko zavukla korijen kako bi probila suviše čvrste, vremenom zadebljale opne zatucanosti bliskih i dalekih pokrajina i pokosi prežitke mantijaškog srednjovjekovlja. Bilo je to kratko stoljeće prepoznavanja razdvojenih srodnika, u kulturnom pluralizmu narodâ koji su davno, pradavno istim mlijekom nadajani, pa otpušteni na razne strane, osuđeni da se u slobodi susretnu tek nakon minulih valova proljetnih evropskih revolucija i romantičarskih sanjarija XIX vijeka, prepoznavši se među sobom, možda po istom - urođenom ili stečenom - biljegu, po usjeklini na preplanuloj koži ili nezdravo zarasloj kosti lomljena uda.

Danas zastupnici ograničenih, parcijalnih interesa povodom jugoslovenskog jubileja govore isključivo o zabludama vremena koje je 
odveć pokojno, pogotovu za pojedince, tada još nerođene, te jednostrano i jednolično, miješajući kontekste, ponavljaju fraze o greškama $u$ izboru puta jugoslovenstva. Kao da to nije bio rezultat ,prirodnih težnji naroda", istorijska nužnost (Билас 1947: 353) i san budno sanjan još od onda kad su se, istovremeno, odreda štampala najveća književna ostvarenja Južnih Slovena - Njegošev „Gorski vijenac”, Mažuranićev Smail-aga, Prešernova „Zdravljica”, Brankove „Pesme” (Поповић 1972: 208). Tada se pobjedi primaklo zaokruženo Vukovo monumentalno djelo. Nije na odmet spomenuti da je baš tih godina izašao i Marksov „Manifest” o bauku koji kruži Evropom, koga je Cankar - neko zgodno reče - kratko, ali snažno prepjevao u „Slugi Jerneju”, toj - rekao bi Boris Ziherl - „pjesmi nad pjesmama" slovenačke socijalističke književnosti.

Ivan Cankar je bio pobornik upravo onog aktivizma koji podrazumijeva da je riječ već čin ${ }^{1}$, angažovanje. Tako, dakle, revoluciju iz 1941. ne možemo ne smatrati praktičnim ostvarenjem onoga što do tada propagiraše angažovana književnost, s Cankarom kao njenom hridi, upravo Engelsovu razbuktanu ,,svijest dotjeranu do strasti” (Јовановић 1972: ${ }^{308)}$. „Tendencioznost umjetničke istine”, zaključuje naš Đorđe Jovanović, ,upravo je ono odakle počinje njena životnost i njena krepkost, a one nekada mogu da se razvijaju do konkretne borbenosti" (1972: 308). Naročit simbolički gest partizana jeste imenovanje jedne od brigada Narodnooslobodilačkog pokreta upravo po Cankaru. Ne opominje li taj akt na Ničeovo shvatanje da umjetnost pomaže da se preživi zakotrljani točak istorije? Ne obistinjuje li snažnu uvjerenost piščevu, iskazanu u proročanskom pokliču: „Narod si bo pisal sodbo sam!” On opravdava i tezu Jovana Popovića koja kaže da u vrijeme takvih iskušenja ,postaju naročito živi oni pjesnici što su izrazili svoje doba, sve patnje i težnje svoga naroda u doba kad su oni živeli” (Поповић 1972, 165), posigurno one iste patnje koje su - Cankar se povjerava - bile atributom njegovog staleža i imena. A da je Cankar poživio do druge svjetske klanice, ne sumnjam da bi rat proveo, budeći usnule moralne energije među okupiranim narodom i narodima, na istoj vojujućoj strani zajedno sa drugom Župančičem ili mlađim sunarodnikom Vidmarom ili Kocbekom, sa raspetom zvijezdom dokučenom i prišivenom na kapu (Ђилас 1947: 89). Pošto nije iskusio apokaliptička iskušenja neprijateljskih ofanziva, a i pošto mu se nije dalo da se u prvom ratu izvojevanoj slobodi pošteno pora-

\footnotetext{
${ }^{1}$ „Delo duha bilo je dvostruko čin pošto je proizvodilo ideje koje su imale da posluže kao osnova društvenim prevratima [...] A taj čin, ma o kojoj knjizi bila reč, uvek se definiše na isti način: on je oslobodilački." (Sartr 1962: 93)
} 
duje, njegova su djela - vrijeme evo kazuje - nakon njega pretrajala, za borbu pripravna. Tako nije slučajno prva predstava u novoosnovanom Jugoslovenskom dramskom pozorištu, neposredno iza rata, u drhtavim euforijama oslobođenja i obnove, bila upravo Cankareva drama „Kralj na Betajnovi".

Cankarevo djelo je tek nacrt za borbe koje odvajkada traju, mijenjajući svoje objave usljed raznolikih konteksta u kojim se jave, uspio pejzaž predočen na platnu od kože palih, za kojim su, daleko, nanizane grudvice i klobuci ustaničkih dimova, tog oslobađajućeg sivila izvijenog sa uspaljenih naših borenja, bivših i budućih. Kultura je takođe borba, nikako pomirljivost i harmonija. Cankar je, prema tome, bio borac, barjaktar slovenaštva u prethodnici socijalizma i jugoslovenstva koje nekoliko godina nakon Prvog svjetskog rata dobija i međunarodno priznato ime.

Ako ikad posumnjamo u njegova uvjerenja, pa i političku pripadnost, obavezno se osvrnimo na biografiju i osjetimo među redovima jezu vlage, hladnoću austrijskih tamničkih zidova, ljubljanskog Grada i leden zadah progona samo zato što je slobodouman, pravdoljubiv Slovenac i Sloven, i to će nas nanovo uvjeriti u Cankarevo patriotsko, ali i nedvosmisleno ljevičarsko opredjeljenje.

Važna epizoda Cankareva života - odigrana u maglovitom praskozorju prvih istupa darovitog literata - svakako jeste reakcija retrogradnih pojava oličenih u ondašnjem ljubljanskom biskupu na Ivanovu tek objavljenu zbirku pjesama, kada se naočigled javnosti dala vidjeti biblioklastična slika napastvovanja ne samo nove riječi, već jedne nove unapređene kulture, kulture koju, inače, ne smije da ima i osjeća sužanj, piše Cankar, ,jer onoga časa kada se bude obazrio oko sebe, kada bude svjestan sramote ropstva, pokušaće svom snagom da se otrese te sramote" (Цанкар 1950: 33). Gorenavedeni čin nije drugo do odveć znana, isključiva inkvizitorska navada, docnije programski definisana za vlade ekstremne desnice. A znamo da su svi ljudi i sve ideje koje stajaše na optuženičkoj klupi svetih institucija odreda isplivali u povijesti življi nego u trenutku svog začeća i postanka. ${ }^{2}$

Jesu li ga te libricidne vatre, ostrvljene na nejako tijelo prve pjesničke zbirke, neotklonjivo progonile toliko dugo i tako intenzivno, da su se u njemu samom užegle, tinjajući u grudobolnim očima? Jesu li se

\footnotetext{
${ }^{2}$ „Crkvena literatura svodi se na uzaludnu apologetiku, to je šaka stisnuta da sačuva dogme koje izmiču; ona se stvara protiv slobode [...] i prestajući da bude slobodan apel na slobodne ljude, prestaje i da bude prava literatura." (Sartr 1962: 87)
} 
to u njima ogledale, provirujući iz nadolazeće pomrčine nove svjetske kataklizme lomače na kojima će se, samo dvije decenije po Cankarevoj fizičkoj smrti, spaljivati živa misleća bića?

Šta je to tako uzbudilo i uzbunilo buskupa Jegliča - mnogo jače no svojevremeno vojvođanske konzervativne krugove pjevanja tzv. „trovača omladine” (Поповић 1972: 201) Branka Radičevića - da je otkupio gotovio cio tiraž tek objavljene „Erotike” kako bi načinio ,poduhvat uniženja", paljevinom se ustremivši na mladalačke stihove? (Zupan Sosič 2018: ${ }^{8)}$ Stvar je više no jasna. Naš Đorđe Jovanović ju ovako tumači: „Nazadne društvene snage nisu u stanju da otkriju istinu [...] Čak i onda kad su morale da uvide i priznaju neke istine, one su uvek ustajale protiv njih" (Јовановић 1972: 305), No time nije potisnuta, niti otklonjena Cankareva slutnja i istina, koja glasi: ,...da sem sam na vsem širokem svetu,/ da sem sam bil, da sem sam ostal" (Cankar 1902:3).

Canakrevo djelo s nipodaštavanjem je uzimano za tendenciju štetnu i nepodobnu. Odlazilo se dotle da se bez osnova - još za pune životne snage piščeve - konstatuje kako je ono, cankarjanstvo, „bilo”, prošlo, iščezlo, iako se, kao vjeran refleks stvarnosti, nikad nije ni prikrilo, a kamoli povuklo. I ovaj jubilej svjedoči da je Cankar tu, pored nas. Sa svakim dubljim ubodom oštrice laži u utrobu istine - koji je i odbljesak sukoba ideoloških suprotnosti - sijevne mu bolećiv, a postojan pogled, ta upaljena vanjska svjetiljka u višeslojnim našim mrakovima, jer ga i dalje bole naše boli. I čitam s ono malo fotografija što čuvaju njegov lik ono što je davno izrekao i zapisao: „Neka čini svako kako mu je dato; ja sam svoje učinio" (Цанкар 1950: 32).

\section{Literatura}

Ivan CANKAR, 1902: Erotika (Nova izdaja), založil L. Schwentner, v Ljubljani

Иван ЦАНКАР, 1950: Одабрани критички и полемички списи, Београд: Ново поколење.

Милован ЂИЛАС, 1947: Чланци 1941-1946, Београд: Култура.

Ђорђе ЈОВАНОВИЋ, 1972: Српска књижевност у сто књига (књига 87), Нови Сад/Београд: Матица српска/Српска књижевна задруга,

Miroslav KRLEŽA, 1972: 99 varijacija, lexicographica, eseji i zapisi, Beograd: Novinsko izdavačko preduzeće Duga. 
Predrag MATVEJEVIĆ, 1977: Književnost i njezina društvena funkcija (Od književne tendencije do sukoba na ljevici), Novi Sad: Radnički univerzitet „Radivoj Ćipranov,

Јован ПОПОВИЋ, 1972: Српска књижевност у сто књига (књига 87), Нови Сад/Београд: Матица српска/Српска књижевна задруга,.

Žan-Pol SARTR, 1962: O književnosti i piscima, Beograd: Kultura,.

Јован СКЕРЛИЋ, 1972: Српска књижевност у сто књига (књига 68), Нови Сад/Београд: Матица српска/Српска књижевна задруга.

Alojzija ZUPAN SOSIČ, 2018: Antologija literature Ivana Cankarja s prevodi v tuje jezike (Pesmi i pripovedi Ivana Cankarja, 8-9), Ljubljana: Center za slovenščino kot drugi in tuji jezik pri Oddelku za slovenistiko.

\title{
Miljan M. Kujača
}

\section{ON SOCIAL ENGAGEMENT AND YUGOSLAVDOM CONCERNING IVAN CANKAR}

\author{
Summary:
}

This writing deals with the issues of social engagement with which a significant number of Ivan Cankar's works are brought into a solid relation. It also considers and deals with Cankar's life and political beliefs. In the context of war events and class turmoil, it mentions the issue of Yugoslavdom. Cankar's fiction, drama and polemics are seen as the true image of society, and with the truth that it indesputably radiates both as a weft and a literary background to the socialist revolution that, in the name of the working class and liberation of the people, will erupt during World War II. It speaks of Cankar's awareness of the situation in society, of the strong belief in the mutual destiny of the South Slav nations and the clear understanding of the necessity for a joint fight against the foreign occupiers, but also against the domestic capitalist oppressors, as well as the struggle for self-determination and unification at last.

Keywords: Cankar, literature, society, engagement, yugoslavdom, war 